DOI: 10.11606/issn.2238-3867.v16i2p338-344

sala preta

ppgac

\title{
O que (quase) não pode ser dito
}

\author{
What (almost) cannot be said
}

\author{
Alvaro Machado
}

Alvaro Machado

Doutorando no Programa de Pós-Graduação em Artes Cênicas da Escola de Comunicações Artes da Universidade de São Paulo. Crítico e teatro e editor.

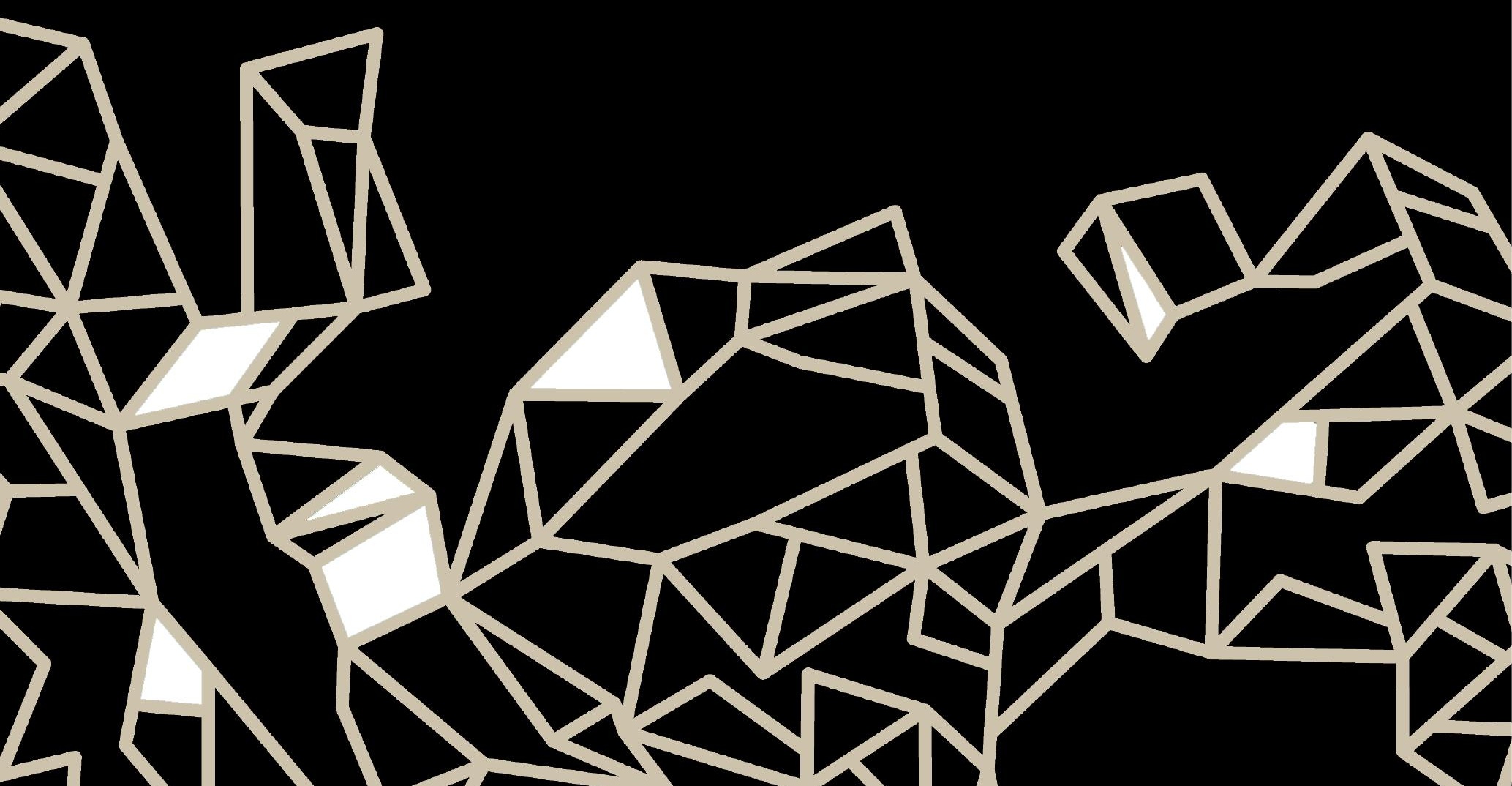




\section{Resumo}

Além de direções para a companhia brasileira de teatro, da qual é fundador, Marcio Abreu assinou dramaturgias e direções para diversos coletivos teatrais e performers, tanto no Brasil como na França. Em 2016, colaborou em texto e assinou a direção de Nós, do Grupo Galpão, de Belo Horizonte, peça analisada neste artigo.

Palavras-chave: companhia brasileira de teatro, Marcio Abreu, Encenação contemporânea, Grupo Galpão.

\section{Abstract}

Along the creations of his companhia brasileira de teatro, founded by him in 2000, Marcio Abreu collaborates with works of several others groups, in Brazil and France. In 2016, Abreu signs both text and direction of Nós, a work by Grupo Galpão, established in the city of Belo Horizonte, Minas Gerais, Brazil. This essay comments this theatrical opus.

Keywords: companhia brasileira de teatro, Marcio Abreu, Contemporary staging, Grupo Galpão.

A par de seu trabalho à frente da companhia brasileira de teatro, com sede no Largo da Ordem, em Curitiba, Marcio Abreu tem colaborado em montagens de diversos outros núcleos cênicos brasileiros. A patentear maturidade criativa em sua trajetória iniciada por volta de 1990, nos dois últimos anos o diretor engajou-se em parcerias profícuas em diversos estados brasileiros, bem como na França. Para o Agon Teatro, jovem ensemble de Londrina com direção de Renato Forin Jr., orientou cenicamente o espetáculo Ovo; escreveu texto e assinou direção de Nômades, do Teatro Poeira (Rio de Janeiro); prosseguiu colaboração com o francês Collectif Jakart, com o qual encenou Nus, Feroces et Anthropophages, criação coletiva desse grupo e da companhia brasileira de teatro; dividiu com Pedro Kosovski a dramaturgia e a direção do espetáculo de dança Enquanto estamos aqui, de Marcia Rubin (RJ); finalmente, encarregou-se de direção e também da dramaturgia (com Eduardo Moreira) de Nós, do Grupo Galpão, de Belo Horizonte, em seu $34^{\circ}$ ano de trajetória. 
Em seis meses, da estreia em maio de 2016, em BH, até breves temporadas em Rio de Janeiro, São Paulo e Porto Alegre, Nós converteu-se em emblema teatral do momento político do país, de troca traumática de governo federal, após complô de partidos supostamente colaboradores e processo de impedimento da presidente eleita em 2014 por via democrática. Para tanto, recorre-se à metáfora da sala de jantar em que sete amigos preparam sopão de cunho ritual-comunitário, regado a indefectível caipirinha, a "bebida nacional". Porém, em meio a esse preparo culinário e a essa convivência, entre perguntas irrespondidas e respostas não solicitadas, acaba-se por determinar a saída do recinto de uma das convivas (a atriz Teuda Bara, 75 anos), expulsa afinal a literais pontapés, para, em uma etapa seguinte, reaparecer e ser novamente coagida, verbal e fisicamente, desta feita a sentar-se e permanecer imóvel em um sofá.

Ao mesmo tempo que tributária da deambulação intrassubjetiva beckettiana, as falas banais e já de saída fragmentárias abandonam, sob o efeito de repetições mântricas, seu sentido imediato para desenhar retrato de um estado de espírito inexprimível em jargão corrente, embora os autores tenham utilizado técnica literária vizinha ao abstracionismo. Sob "provocações" lançadas pelo diretor, conhecedor do trabalho do grupo desde 1994, e de exercícios-solo que a Companhia já empreendia nos últimos anos, a mais chã esfera do quotidiano (“Eu como de tudo!", "É para refrescar!” etc.) e do fait divers de noticiário com valor de lugar-comum ("A coisa não tá fácil, dizem que vai ficar mais feia!" etc.) converte-se no desenho magnificado da insatisfação e perplexidade com os rumos do país em sua escalada para o neoliberalismo econômico em chave assumidamente autoritária. $\mathrm{O}$ bordão mais frequente da matrona no centro do tablado, "Do que vocês estão falando?" - convertido por vezes no "Do que é mesmo que a gente está falando?", típico do escape canhameiro - estabelece, por sua vez, paralelo direto com a repetida indagação de Hamm na dramaturgia pós-catástrofe de Fim de partida (1957): "O que está acontecendo?" questão simultaneamente intrassubjetiva e dirigida à plateia, como na peça de Beckett citada (KUNTZ; NAUGRETTE; RIVIÈRE, 2012, p. 47).

A partir de processos de autoescrutinação aos quais os atuantes foram lançados pelo diretor - em especial a partir da pergunta "De que maneira respondemos ou reagimos ao mundo como ele nos chega hoje?" (GALPÃO, 2016, p. 9) -, delineou-se retrato de parcela significativa do povo brasileiro sob 
sequestro de liberdades de expressão e destituição de sua representatividade política, a ponto de provocar nas plateias, ao final de noventa minutos, catarse saudavelmente distante dos sentimentos de terror ou piedade do sistema teatral aristotélico. Assim, após reciclar a seu modo as tragédias de traição regicida e matricídio sacrílego motivadoras da antiga catarse, Nós evolui para o transe dionisíaco coletivo, em orgia báquica nos limites do possível, propiciada, depois da cena final, pela transformação do pódio teatral em pista de baile, à qual os espectadores são convidados pelos atores, com adesão maciça.

Tal procedimento de demolição da "quarta parede" instaura-se já no prólogo, com luzes de serviço acesas e em modo de mansidão "caseira", ou "mineira", e o elenco a convidar parte do público a inusuais plateias laterais ao tablado, cuja função não é apenas ampliar a capacidade do recinto em lugares. Na mesma direção, aos espectadores serão servidas a bebida e a comida preparadas em vivo, e, nos momentos em que a confecção do prato deforma-se em contornos de grotesco, o público será borrifado com sobras de vegetais e líquidos.

Também grotesca, a desorientar o espectador com seu golpe súbito, é a configuração cênica a contrapor dois atores maduros, Teuda Bara e Eduardo Moreira, a despirem-se, pintarem seus membros com palavras de urgência e banharam-se em lama, evocativa da tragédia ecológica e social de Mariana, Minas Gerais. Corpos tornados, assim, testemunhos eloquentes da catástrofe, tanto em sentido literal como na acepção trágica do termo, ainda que redimensionado contemporaneamente - como assinalado por Sarrazac, entre outros -, uma vez que se torna impossível definir claramente um centro irradiante para as ações dos participantes do ágape (MORAES 2012, p. 15).

Erigido com "blocos" de atitudes/caracterizações amalgamadas de forma coesa por cada um dos sete integrantes, como nos elementos combinados de uma composição construtivista, o espetáculo assume-se integralmente enquanto montagem, no pleno sentido de sua acepção. A montagem compõe-se, porém e sobretudo, de imobilidades, rigidezes, entraves e, consequentemente, não ações, propiciando ao Galpão seu encontro definitivo com a problemática tchekhoviana, esboçado na encenação in vitro de As três irmãs (2009) - sob direção de Enrique Diaz, reelaborada em edição cinematográfica por Eduardo Coutinho no longa-metragem Moscou -, aproximação malograda em muitos vetores, no entanto, na colaboração do núcleo mineiro com o diretor russo Jurij Alschitz (Eclipse, 2012). 
Quanto ao trabalho de mise en place - mais que de mise-en-scène, uma vez que a criação considera de saída todo o edifício teatral e sua arquitetura espacial e sonora, bem como reage diretamente à disposição do público, seja física ou emocional (SANTOS, 2014, f. 124) -, o procedimento de instauração de clima de cumplicidade, familiaridade e conforto como premissa falsa a preambular choques e ribombos sígnicos de extrema contradição já constituía recurso do diretor Marcio Abreu em PROJETO bRASIL, também de 2016, com a companhia brasileira. Nessa obra, o substrato fornecido à dramaturgia também era provido pelos atores, músicos e colaboradores da Companhia, em textos híbridos de documento sociológico e depoimento pessoal, porém com lastro diverso de experiência e laços internos mais recentes que os do Galpão, e por isso mesmo alicerçados em pesquisas de campo promovidas em cidades de cinco regiões brasileiras, ao longo de mais de um ano.

Não mais estilhaçada em esquetes de naturezas díspares, como em PROJETO bRASIL, mas depurada no quadro-síntese do jantar que evolui de congraçamento a conflagração - ainda que com intermissões líricas estratégicas de canto solo, coral e banda ao vivo constituída pelos próprios atores -, a proposta anterior da brasileira de um teatro-depoimento do atuador alcança patamar de excelência com o fundamento humano ricamente facetado do Galpão, iluminado por exercício de três décadas em caminhos estéticos e consequentes posicionamentos políticos, em colaborações com diretores de talhes tão diversos como Gabriel Villela, Yara de Novaes, Paulo José, Cacá Carvalho, Paulo de Moraes e Marcio Abreu, entre outros.

Do ponto de vista da escrita, Nós apaga, na argamassa obtida, os traços biográficos originários, de múltiplos discursos, para obter dramaturgia de coesão passível de encenação por qualquer grupo com domínio técnico suficiente para malabarizar a miríade de indicações e rubricas apontadas no roteiro. Mesmo com legendas em língua estrangeira e público desvinculado da realidade tratada em seu subtexto, a obra irá produzir impactos emocionais e estéticos, bem como reflexão por parte do espectador.

A complexidade e o detalhamento de rubricas e indicações de autoria/ direção, a apontar centenas de movimentos e micromovimentos, converte a criação em partitura coreográfico-musical, com leitmotivs e questões rítmicas internas. Paralelos, cruzados e autônomos, os discursos verbo-visuais erigem 
polifonia em torno de um ponto de vista ou tema inicialmente unívoco, até a desconstrução em cacofonia. Assim, após uma primeira exercitação de diálogos e gestuais em registro corriqueiro, ainda apoiada no jogo de cena tradicional, as imagens animadas e suas pontuações faladas passam a propor oximoros e paradoxos, a valem-se, ainda, da célebre habilidade da prosódia mineira de comentar, em gordas entrelinhas, o que não pode, ou não convém, ser dito.

No espectador, que testemunha o movimento da enervante "dança das cadeiras", aliado ao curto-circuito de sentidos provocado pela enunciação de textos em looping (repetição obstinada e gradualmente corrompida), reverbera em crescente emocional, vizinho da exasperação. Como discorre Joseph Danan (2012, p. 125) em verbete enciclopédico, "o valor de movimento da obra reflete-se no movimento que ela engendra no espectador [...], movimento chamado, às vezes, 'emoção' e que pode tornar-se, então, impulso para o pensamento". Em especial para o público brasileiro, o ecoar inequívoco - tanto mais potente porque interdito/intradito - de episódios políticos escabrosos e recentes provoca, com frequência, choro e exclamações de inconformismo. Sob lentes e luzes cênicas ampliadoras, o espelho da retina embaça, range e rompe.

Na partitura cênica, em que o texto representa apenas um dos instrumentos de alcance, o elemento musical e lírico assume proeminência, todavia, em quatro clímax e anticlímax apoiados em canções de ressonância afetiva (do ponto de vista de grupo) e histórica. Com apoio do músico Felipe Storino, da companhia brasileira de teatro, corresponsável por trilha e efeitos sonoros de autêntico peso narrativo, os intérpretes convertem-se em banda mambembe, grotesca em sua seminudez e promiscuidade corporal fonte concomitantemente de prazer e constrangimento -, para entoar duas canções com afinação de coerência interna, fruto de óbvio aprimoramento técnico. Assim, a fala faz-se lamento-solo (vocal e, num segundo momento, de trombone) instaurado epicamente, mas sem necessidade de fissura, a avançar rumo ao transcendente por meio de novo paradoxo, obtido desta feita com a melodia e a letra pungentes do samba-canção "Lama", de Paulo Marques e Alyce Chaves, popularizado em 1952 na voz da carioca Linda Rodrigues e apresentado, na montagem, com efeitos de eco, a potencializar seu subtexto de despudorada autoexposição de solidão em meio ao coletivo. Em ponto mais adiante, a "Balada do lado sem luz", composição de Gilberto Gil 
a denunciar impossibilidades em meio à ditadura brasileira, de 1976, recebe interpretação coral de arranjo a cappella destinado a atualizar seu caráter de esperança desesperançada.

Em plano puramente literário, a peça explicita um dos materiais utilizados no embasamento dramatúrgico, com a publicação, em programa, de trechos de $O$ ódio à democracia, de Jacques Rancière (2014, p. 87), que denunciam a via da intriga política como a pior forma de governo possível . Já no desenlace, em que a sopa pronta é servida à atriz decana inteiramente manietada, os versos oximoros do poema "Agradecimento", da polonesa Wisława Szymborska (2011, p. 33), são enunciados, à maneira de "alimento espiritual", alternadamente a goles de caldo destinado a revigorar um corpo todavia imobilizado: "Devo muito/ aos que não amo./ O alívio de aceitar/ que sejam mais próximos de outrem./ A alegria de não ser eu/ o lobo de suas ovelhas".

\section{Referências bibliográficas}

DANAN, J. Movimento. In: SARRAZAC, J.-P. (Org.). Léxico do drama moderno e contemporâneo. São Paulo: Cosac Naify, 2012.

GALPÃO. Nós. São Paulo: Sesc-SP, 2016.

KUNTZ; NAUGRETTE; RIVIÈRE. Catástrofe. In: SARRAZAC, J.-P. (Org.). Léxico do drama moderno e contemporâneo. São Paulo: Cosac Naify, 2012.

SANTOS, M. T. L. (Org.). Balagan Companhia de Teatro. São Paulo: Balagan, 2014. MORAES, F. Introdução. In: SARRAZAC, J.-P. (Org.). Léxico do drama moderno e contemporâneo. São Paulo: Cosac Naify, 2012

RANCIÈRE, J. O ódio à democracia. São Paulo: Boitempo, 2014.

SARRAZAC, J.-P. Léxico do drama moderno e contemporâneo. São Paulo: Cosac Naify, 2012.

SZYMBORSKA, W. Poemas. São Paulo: Companhia das Letras, 2011.

Recebido em 05/10/2016

Aprovado em 28/10/2016

Publicado em 21/12/2016 